\title{
Vanadium carbides in shungite
}

\author{
Vladimir V. Kovalevski and Igor A. Moshnikov \\ Institute of Geology, Karelian Research Centre, Russian Academy of Sciences, \\ Pushkinskaya St. 11, Petrozavodsk, Russia \\ Correspondence: Vladimir V. Kovalevski (kovalevs@krc.karelia.ru)
}

Received: 15 July 2021 - Revised: 27 December 2021 - Accepted: 7 January 2022 - Published: 16 February 2022

\begin{abstract}
Four types of shungite rocks containing $98.2 \mathrm{wt} \%, 22.2 \mathrm{wt} \%, 21.6 \mathrm{wt} \%$ and $22.4 \mathrm{wt} \% \mathrm{C}$ and 416 , 311,78 and $182 \mathrm{ppm} \mathrm{V}$ were studied, while the ash from these samples contained 23120, 400, 100 and $234 \mathrm{ppm} \mathrm{V,}$ respectively. The presence of two vanadium carbides, $\mathrm{V}_{2} \mathrm{C}$ and $\mathrm{V}_{6} \mathrm{C}_{5}$, in samples of shungite with a content of $98.2 \mathrm{wt} \% \mathrm{C}$ has been revealed by energy dispersive spectroscopy (EDS) and selected-area electron diffraction (SAED). The vanadium carbides revealed are monocrystalline and encapsulated in a carbon shell and thus are the first well-crystallized natural examples of $\mathrm{V}$ carbides. The shungite-bearing rocks are Lower Proterozoic in age (2.0-2.1 Ga), and the encapsulation of vanadium carbides in carbon shells explains their good preservation during this time. Parageneses of vanadium carbide and roscoelite have also been found, indicating that roscoelite in shungite rocks may be a secondary mineral formed during the decomposition of vanadium carbide. It is possible that the decomposition of vanadium carbides due to the destruction of carbon shells with the formation of roscoelite occurred during the $1.8 \mathrm{Ga}$ Svecofennian orogeny when the sediments were affected by greenschistfacies metamorphism. Particles encapsulated in carbon shells were also revealed in the shungite rock containing $22.2 \mathrm{wt} \% \mathrm{C}$ and $311 \mathrm{ppm} \mathrm{V}$, for which high shielding effectiveness is observed in a wide frequency range.
\end{abstract}

\section{Introduction}

In the past few decades, special attention has been paid to transition metals, in particular vanadium, which belongs to the group of critical elements and is widely used in metallurgy for the production of high-strength steels, in the chemical industry as a catalyst and in materials science for the production of special ceramics and materials for nuclear reactors. However, vanadium and its compounds are also toxic substances (Gustafsson, 2019). Vanadium is extracted only as a byproduct as no independent deposits are known; it is also characterized by having a traceable relationship with organic matter (Parnell, 1988; Bielowicz, 2020). Crude oils and bitumens generally contain up to $2000 \mathrm{ppm} \mathrm{V}$ in the form of metalloporphyrin and non-porphyrin species (Filby, 1994). Vanadium metalloporphyrins are assumed to be formed during the early diagenesis of parent rocks and are associated with the sedimentary environment, whereas vanadium nonporphyrin complexes are due to the release of metal complexes from kerogen during catagenesis (Filby, 1994). However, for western Kentucky (USA) coals, it has been shown that the bulk $\mathrm{V}$ is a product of volcanic activity, formed mainly as a result of geochemical alterations in volcanic ash (Premovič et al., 1997). In the light of the problem discussed, black Precambrian rocks (shungite rocks) occurring in Karelia, northwestern Russia, are of particular interest (Buseck et al., 1997) for their high $\mathrm{V}$ concentrations of up to $3000 \mathrm{ppm}$ (Golubev and Galdobina, 1985), indicating the "geochemical vanadium profile" of shungite rocks (Marakushev and Marakushev, 2008). The main conclusions on the concentrations and form of $\mathrm{V}$ in organic matter are generally based on geochemical data and mainly on the results of chemical analysis showing the average content of elements in the rock. To date, no mineralogical studies have actually been carried out on the distinctive accumulation pattern and forms of vanadium in carbon-bearing rocks.

The goal of this contribution is to better understand the characteristics of vanadium-containing mineralization in shungite as an example of organic matter, to study the sources of vanadium and to assess the possible influence of vanadium mineralization on the properties of shungite rocks. 


\section{Materials and methods}

Shungite (Sh1), carbon-rich rock with a carbon content of about $98 \mathrm{wt} \%$ from the Shunga locality (Buseck et al., 1997), was used to understand the morphology and composition of micro-sized vanadium-containing minerals. To assess the possible effect of vanadium-bearing mineralization on the properties of shungite rocks, a shungite rock (ShR1) of the second stratigraphic level was selected (Deines et al., 2020), in which micro-sized minerals encapsulated in a carbon shell were previously revealed. This rock consists of rock-forming minerals, such as quartz, albite and chlorite, and contains $22.2 \mathrm{wt} \%$ carbon and an elevated vanadium concentration. For comparison with this sample, shungite rocks (ShR2 and ShR3) with a similar content of carbon and rock-forming minerals but with no particles encapsulated in a carbon shell were selected. The amount of carbon in the rock was chosen as a major comparison criterion since it was planned to compare the presence of particles encapsulated in the carbon shell with the electro-physical properties of the shungite rock.

A VEGA II LSH scanning electron microscope (TESCAN, Brno, Czech Republic) equipped with an energy dispersive spectrometry (EDS) Energy 350 system and an SDD $\mathrm{X}$-Act3 detector (Oxford Inca Energy, Oxford, UK) was used to study the sample surface, to perform electron microprobe analysis and to visualize element distribution maps. A JEOL 2000FX electron microscope, operating at $200 \mathrm{kV}$, was used for high-resolution transmission electron microscopy (HRTEM), selected-area electron diffraction (SAED) and EDS measurements. An EM-125 transmission electron microscope, operating at $100 \mathrm{kV}$, was used for the routine study of shungite rocks. Powdered samples for transmission electron microscopy were placed onto lacy carbon films that were deposited on copper grids. SAED patterns were recorded photographically and processed, as reported elsewhere (Kovalevski et al., 2001).

Trace element concentrations were determined by mass spectrometry with inductively coupled plasma (ICP-MS). Element abundances were measured on a Thermo Scientific XSeries 2 ICP-MS quadrupole mass spectrometer (Thermo Scientific, Waltham, MA, USA) following the method of Svetov et al. (2015). The analyses were carried out on several subsamples of $100 \mathrm{mg}$ obtained from the ash of shungite samples that were decomposed as a result of treatment with hydrochloric, nitric and hydrofluoric acids in an open system. The measured concentration values are characterized by low relative standard deviation values; the percentages are lower than $7 \%$ for most elements.

A comparative study of carbon from shungite rocks was carried out using a Nicolet Almega XR Raman spectrometer with a green laser (532 nm, Nd:YAG). The spectra were collected at $2 \mathrm{~cm}^{-1}$ spectral resolution. The spectrometer was calibrated before each analytical session by "zero-point" centering and by analyzing a $\mathrm{Si}$ standard with a characteristic Si Raman band at $520.4 \mathrm{~cm}^{-1}$. A confocal microscope with a $50 \times$ objective was used to focus an excitation laser beam on the sample and to collect a Raman signal from a $2 \mu \mathrm{m}$ diameter area. Raman spectra were acquired in the 800 $3200 \mathrm{~cm}^{-1}$ spectral region, with the $30 \mathrm{~s}$ exposition time. To reduce the experimental error, Raman spectra from about 10 shungite areas were recorded, depending on the divergence of test values for each sample, and the data obtained were statistically processed. Raman spectral data, such as peak position, band area and band width (full width at half maximum, FWHM), were determined using OMNIC software with a Gaussian-Lorentzian function as described in more detail by Chazhengina and Kovalevski (2017). Mean values, estimated for each sample from several spot analyses, and standard deviation (less than 0.03), which may characterize the heterogeneity of the carbonaceous matter of a sample, were calculated for the R2 parameter of the Raman spectra (Beyssac et al., 2003). The shielding effectiveness powders of shungite rock measurements were carried out using the coaxial transmission line method in the frequency range of $0.01-1000 \mathrm{MHz}$ as reported elsewhere (Moshnikov and Kovalevski, 2018).

\section{Results}

\subsection{Vanadium mineralization in shungite}

Shungite with a carbon content of about $98 \mathrm{wt} \%$ from the greenschist facies (Grew, 1974; Buseck et al., 1997; van Zuilen et al., 2012) is an extreme member in bitumen transformation according to the Van Krevelen diagram (Cornelius, 1987). Carbonaceous matter is a major component of shungite and shungite rocks, but mineral components affect the many properties of rocks and carry genetic information related to the interaction of carbonaceous matter and mineral components (van Zuilen et al., 2012). Shungite is enriched in a variety of trace elements (Golubev and Galdobina, 1985; Ketris and Yudovich, 2009), including vanadium. ICP-MS analysis of the ash of the selected samples revealed a significant content of vanadium in the selected samples (Table 1). The highest content of vanadium was determined in shungite Sh1 and shungite rock ShR1.

The study of shungite Sh1 using scanning electron microscopy (SEM) with an energy dispersive spectrometry (EDS) in the element distribution map visualization mode revealed a significant number of V-bearing micro-dimensional inclusions in the carbon matrix (Fig. 1a). The V-bearing inclusions present in shungite are not sulfides, unlike, for example, $\mathrm{Zn}$ sulfides shown in Fig. $1 \mathrm{~b}$ for comparison. It should be noted here that the form of sulfides in the form of microspherulites is unusual for inclusions in carbonaceous matter (Rogerson et al., 2017; Baumgartner et al., 2020).

Further investigation of numerous shungite samples using SEM and EDS revealed some features of vanadium mineralization directly related to the carbonaceous substance. 
Table 1. The content of some trace elements in the ash of shungite (Sh1) and shungite rock (ShR1, ShR2, ShR3) samples, determined by mass spectrometric analysis with inductively coupled plasma (relative standard deviation values are lower than $7 \%$ ).

\begin{tabular}{lrrrrrrrrr}
\hline Sample & $\begin{array}{c}\text { Carbon } \\
\text { content }\end{array}$ & \multicolumn{8}{c}{ Trace elements in the ash (numerator) and the initial } \\
\cline { 3 - 10 } & $($ wt \%) & $\mathrm{V}$ & $\mathrm{Cr}$ & $\mathrm{Mn}$ & $\mathrm{Co}$ & $\mathrm{Ni}$ & $\mathrm{Cu}$ & $\mathrm{Zn}$ & $\mathrm{Zr}$ \\
\hline Sh1 & 98.2 & $\frac{23120}{416}$ & $\frac{125}{2.3}$ & $\frac{1670}{30}$ & $\frac{1175}{21}$ & $\frac{14870}{268}$ & $\frac{7680}{138}$ & $\frac{3600}{65}$ & $\frac{206}{3.7}$ \\
ShR1 & 22.2 & $\frac{400}{311}$ & $\frac{176}{137}$ & $\frac{2120}{1650}$ & $\frac{51}{40}$ & $\frac{143}{111}$ & $\frac{260}{202}$ & $\frac{308}{240}$ & $\frac{90}{70}$ \\
ShR2 & 21.6 & $\frac{100}{78}$ & $\frac{70}{55}$ & $\frac{360}{282}$ & $\frac{13}{10}$ & $\frac{47}{37}$ & $\frac{141}{111}$ & $\frac{76}{60}$ & $\frac{38}{30}$ \\
ShR3 & 22.4 & $\frac{234}{182}$ & $\frac{218}{169}$ & $\frac{271}{210}$ & $\frac{18}{14}$ & $\frac{602}{467}$ & $\frac{372}{289}$ & $\frac{742}{576}$ & $\frac{68}{53}$ \\
\hline
\end{tabular}

* Calculated data based on the carbon content in the samples.
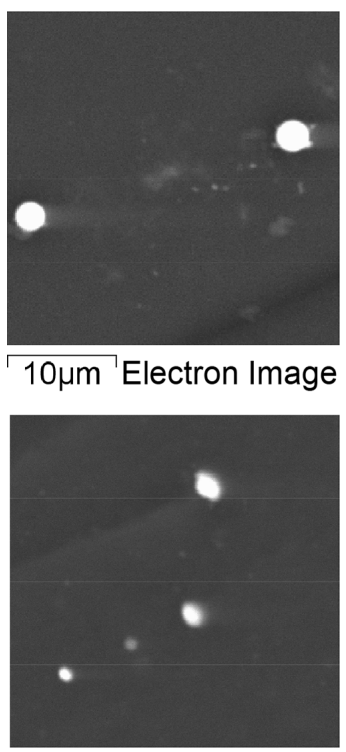

$10 \mu \mathrm{m}$ Electron Image

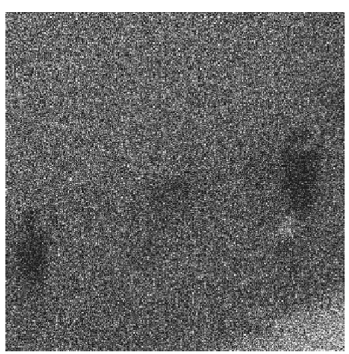

CKa1_2

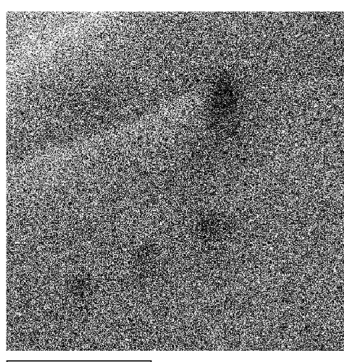

C Ka1_2

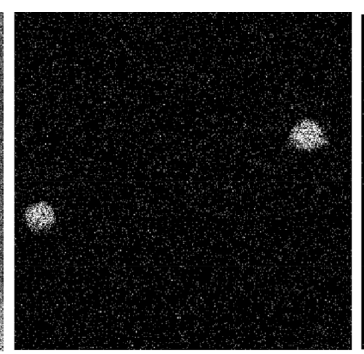

$\mathrm{SKa} 1$

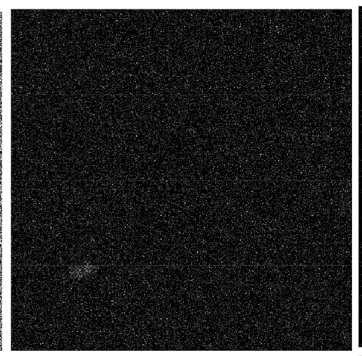

S Ka1
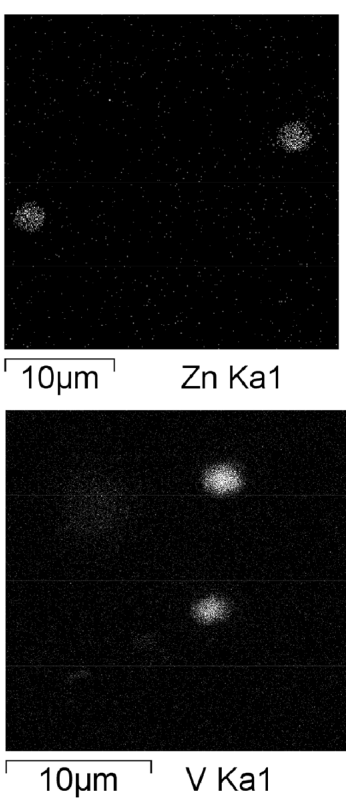

Figure 1. Element distribution maps of the Sh1 regions with V- and Zn-bearing micrometer-sized inclusions.

Mineral inclusions containing significant vanadium measure from about $0.1 \mu \mathrm{m}$ (nanocrystals) to several micrometers across and are distributed fairly evenly in the carbon matrix. Figure 2 shows the most representative inclusions from 3 to $6 \mu \mathrm{m}$ across. EDS analysis of such small-sized minerals located in the carbon matrix displays a considerable error and is, in fact, semi-quantitative. According to the results of scanning electron microscopy and EDS analysis, all the identified vanadium-containing minerals were conditionally divided into three types based on morphology (Fig. 2) and the presence of oxygen (Table 2). The presence of carbon and vanadium, sometimes with traces of sulfur, iron, nickel and arsenic, was revealed for several dozens of rounded minerals of Type I (Fig. 2a). Type I grains differed in the ratio of vanadium to carbon and the presence of various trace elements. To demonstrate this difference, Table 2 shows the extreme compositions of Type I grains. Note that oxygen peaks are hard to identify against vanadium peaks in energy-dispersion analysis due to the proximity of $L_{\alpha}(\mathrm{V})$ and $K_{\alpha}(\mathrm{O})$ radiation energies $(0.5113$ and $0.5249 \mathrm{keV}$, respectively). However, in our case, oxygen was not detected using standard software, and its additional introduction into the calculations did not improve the recovered total energy dispersion spectrum. Thus, minerals of this type can be tentatively assigned to vanadium carbides, of which at least five non-stoichiometric compounds have been reported, ranging in $\mathrm{V}: \mathrm{C}$ ratio from $\sim 2: 1$ to $\sim 1: 1$ (Lipatnikov et al., 1999; Hu et al., 2006; Okamoto, 2010).

Type II minerals are aggregates with irregular outlines (Fig. 2b). Their composition could not be determined due 

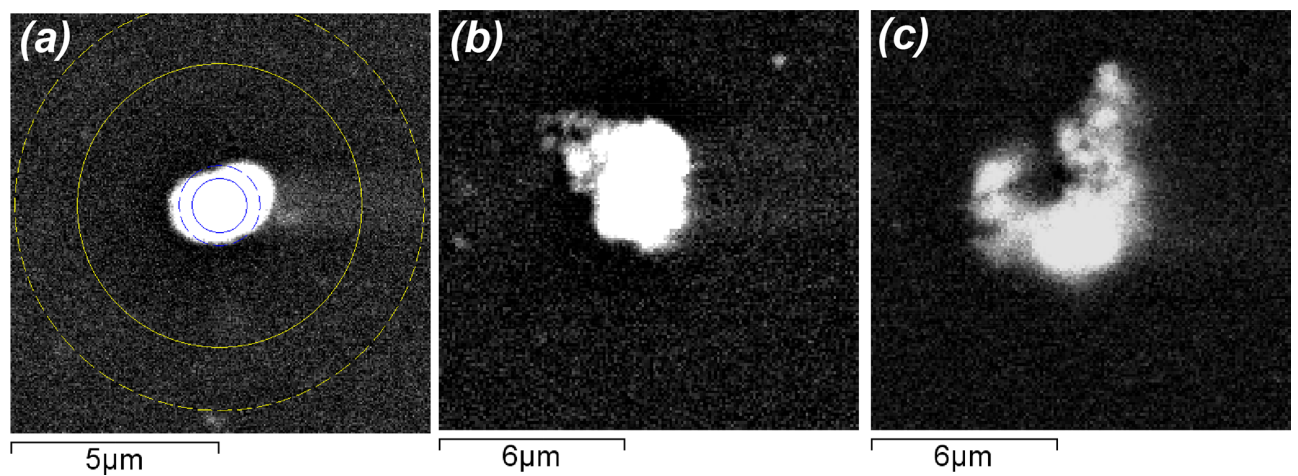

Figure 2. Scanning electron microscopic images in backscattered electrons of various types of vanadium-bearing (a, b, c) minerals located in a carbon (shungite) matrix of Sh1 samples. Panels (a), (b) and (c) show representative Type I, Type II and Type III grains, respectively. The circles in Fig. 2a correspond to the minimum and maximum regions of electron scattering and excitation of characteristic X-ray radiation. That is, all the spectra shown in Table 2 contain a contribution from the carbon matrix and micro-sized inclusions, are semi-quantitative, and are given to assess changes in the compositions of vanadium-bearing minerals of various types.

Table 2. EDS composition (in atomic \%) of various types of vanadium-bearing minerals in shungite.

\begin{tabular}{|c|c|c|c|c|c|c|}
\hline \multirow{3}{*}{$\begin{array}{l}\text { Chemical } \\
\text { element }^{\mathrm{a}}\end{array}$} & \multicolumn{6}{|c|}{ Vanadium-bearing minerals } \\
\hline & \multicolumn{2}{|c|}{$\begin{array}{c}\text { Type I } \\
\text { V carbide } \\
\text { (presumably) }\end{array}$} & \multicolumn{2}{|c|}{$\begin{array}{c}\text { Type II } \\
\text { Eroded V carbide }\end{array}$} & \multicolumn{2}{|c|}{$\begin{array}{c}\text { Type III } \\
\text { V carbide and } \\
\text { roscoelite paragenesis }\end{array}$} \\
\hline & Mineral 1 & Mineral 2 & $\begin{array}{r}\text { Mineral } \\
\text { association } 1\end{array}$ & $\begin{array}{r}\text { Mineral } \\
\text { association } 2\end{array}$ & $\mathrm{~V}$ carbide & Roscoelite \\
\hline $\mathrm{C}^{\mathrm{b}}$ & 84.26 & 90.85 & 69.22 & 30.44 & 81.76 & 69.88 \\
\hline $\mathrm{Si}$ & 0.31 & & 0.74 & 0.84 & 0.72 & 4.26 \\
\hline $\mathrm{V}$ & 14.74 & 7.73 & 17.41 & 50.46 & 14.08 & 2.34 \\
\hline $\mathrm{Fe}$ & 0.69 & 0.33 & 0.67 & 2.42 & 0.65 & \\
\hline S & & 0.39 & 0.53 & 1.64 & & \\
\hline $\mathrm{Ni}$ & & 0.39 & 0.48 & 9.01 & & \\
\hline As & & 0.31 & 0.22 & & & \\
\hline $\mathrm{O}$ & & & 10.47 & 2.49 & 2.34 & 20.52 \\
\hline $\mathrm{Al}$ & & & 0.25 & 0.16 & 0.24 & 1.7 \\
\hline $\mathrm{Mg}$ & & & & & 0.03 & 0.18 \\
\hline $\mathrm{K}$ & & & & 2.54 & 0.18 & 1.12 \\
\hline
\end{tabular}

a The maximum error in determining the elements was $( \pm$ wt $\%)$ : $\mathrm{C}-2.10 ; \mathrm{Si}-0.44 ; \mathrm{V}-0.96 ; \mathrm{Fe}-0.19 ; \mathrm{S}-0.37 ; \mathrm{Ni}-0.15$; As $-0.05 ; \mathrm{O}-1.98 ; \mathrm{Al}-0.23 ; \mathrm{Mg}-0.04 ; \mathrm{K}-0.21 .{ }^{\mathrm{b}} \mathrm{C}-$ the carbon content includes the carbon of the matrix and micro-sized inclusions.

to their small size. Total EDS microanalysis of this mineral association revealed the prevalence of carbon and vanadium in the presence of oxygen, as well as traces of aluminum, silicon, sulfur, iron, nickel and arsenic. It was impossible to carry out a separate EDS analysis of the minerals of these associations, and therefore the extreme compositions of these mineral associations are given in Table 2. In this case, the oxygen concentration is too low for the formation of oxides of the elements present in the total spectrum. Associations of clearly separate grains were assigned to Type III of vanadium-containing minerals (Fig. 2c), for which it was possible to conduct a more or less representative EDS analysis (Table 2), as well as to draw con- clusions concerning the paragenesis of vanadium carbide and vanadium-containing mica, roscoelite. For this type of vanadium-containing grains, extreme compositions are not given; instead the compositions in one example of this paragenesis are tabulated (Table 2).

With an increase in the size of the vanadium-rich inclusions found during the EDS study (Type II, for example; Fig. 2b), the contribution from the carbon matrix decreases (Table 2, mineral association 2), and the approximate composition of the inclusions can be better constrained; for example, these inclusions are more likely $\mathrm{V}_{2} \mathrm{C}$ rather than $\mathrm{VC}$ or $\mathrm{V}_{8} \mathrm{C}_{7}$. Nonetheless, the EDS data are too sparse to determine more specifically the composition of the vanadium car- 
bides in shungite. This identification required a combination of HRTEM, SAED and EDS methods.

The study of shungite using transmission analytical electron microscopy equipped with an EDS spectrometer revealed about a dozen individual vanadium-bearing oxygenfree minerals that were either rounded or had faint traces of crystallographic faceting. All of those are single crystals as can be seen from SAED patterns (as, for example, in Fig. 3a, b). All the SAED patterns obtained were analyzed according to the International Centre for Diffraction Data (ICDD) database of synthetic vanadium carbides and based on the position of diffraction maxima and calculated angles between them. The main part of them were unambiguously interpreted as SAED patterns of vanadium carbide $\mathrm{V}_{2} \mathrm{C}$ (ICDD - 01-071-1258) and several as SAED patterns of vanadium carbide $\mathrm{V}_{6} \mathrm{C}_{5}$ (ICDD - 01-080-2287). However, for some SAED patterns, no coincidence was found with the vanadium carbides available in the ICDD database in terms of the position of the maxima and the calculated angles between them. Synthetic vanadium carbide $\mathrm{V}_{2} \mathrm{C}$ (ICDD - 01071-1258) belongs to the orthorhombic crystal system and the $P b c n$ space group with crystal lattice parameters $-a$, $b$ and $c$ equal, respectively, $0.457,0.5742$ and $0.5026 \mathrm{~nm}$. Vanadium carbide $\mathrm{V}_{6} \mathrm{C}_{5}$ (ICDD - 01-080-2287), belongs to the monoclinic crystal system and the $C 2 / m$ space group with the parameters of the crystal lattice $-a, b$ and $c$ equal, respectively, $0.53,0.92$ and $1.02 \mathrm{~nm}$, and $\beta$ equals $100.2^{\circ}$. Several articles mention occurrences of highly reduced $\mathrm{V}$ minerals native vanadium and kishonite $\mathrm{VH}_{2}$ (Ostrooumov and Taran, 2016; Bindi et al., 2020). However, there is no mention of natural vanadium carbide, and we can state that the minerals found in shungite are the first well-crystallized natural examples of $\mathrm{V}$ carbides.

The most important feature of the vanadium carbides found in shungite is that they are surrounded (encapsulated) by a carbon film (indicated by arrows in Fig. 3), in which the degree of ordering of the carbon layers is greater than in the carbon matrix. Nonetheless, the individual carbon layers in the film are distinguished with difficulty due to the small size of the film compared to the thickness of the material being investigated.

In addition to micro-sized single crystals of vanadium carbide, parageneses vanadium carbide and roscoelite were also found in shungite (Fig. 4). Between vanadium carbide and mica mineral, roscoelite was revealed in three nano-sized regions with an increased vanadium content (Fig. 4, arrowed). The dark regions (indicated by an arrow) with greater electron scattering in the absence of diffraction contrast correspond to a substance with a higher atomic weight against carbon. These regions extend from the vanadium carbide to a new formation, which is probably due to the diffusion transfer of vanadium to the site of roscoelite formation. Therefore, roscoelite in shungite may be a secondary mineral formed during the decomposition of vanadium carbide.
Roscoelite is associated with a special feature, namely individual fragments of a carbon film revealed at its surface (Fig. 5). Similar films of partially graphitized carbon were encountered at the surface of chlorite and quartz, which are believed to have triggered localized partial graphitization of sedimentary organic material during metamorphism in shungite rocks (van Zuilen et al., 2012). In our case, only a fragment of a carbon film is observed, which cannot be called a graphite film due to both the absence of three-dimensional reflections of graphite on the SAED patterns and a greater interlayer distance with respect to graphite at 0.35 to $0.36 \mathrm{~nm}$.

\subsection{Vanadium distribution in shungite rocks}

Based on the described features of vanadium-containing mineralization in shungite and its possible influence on the electro-physical properties, a comparative study of shungite rocks selected from different levels of the Zaonezhskaya structure was carried out (Deines et al., 2020). One of the samples (ShR1, Table 1) was purposefully taken as a rock in which previously routine transmission electron microscopic (TEM) studies revealed the presence of a significant number of micro- and nano-scale inclusions encapsulated by carbon shells (Fig. 6). Samples ShR2 and ShR3 with the same carbon content, which primarily determines the electrical conductivity and shielding effectiveness, were selected for comparative analysis. Since the electro-physical properties are also significantly affected by the ordering of carbon, Raman spectroscopy was used to estimate it (Deines et al., 2020).

The Raman spectra for all selected samples are consistent with poorly ordered carbonaceous material (Beyssac et al., 2002, 2003; van Zuilen et al., 2012). The first-order region of the shungite Raman spectra shows two bands: D1 at about $1350 \mathrm{~cm}^{-1}$ and $\mathrm{G}$ band at about $1600 \mathrm{~cm}^{-1}$. In the secondorder region, shungite samples are mainly characterized by bands S1 of about $2680 \mathrm{~cm}^{-1}$ and S2 of about $2900 \mathrm{~cm}^{-1}$ (Deines et al., 2020). The parameter R2 corresponding to the $\mathrm{D} 1 /(\mathrm{G}+\mathrm{D} 1+\mathrm{D} 2)$ area ratio, which is higher than 0.5 for poorly ordered and lower than 0.5 for well-ordered carbon, was used to estimate the structural ordering of shungite samples (Beyssac et al., 2003). The shungite sample (Sh1) is characterized by a value of $\mathrm{R} 2$ equal to 0.72 . For samples ShR1, ShR2 and ShR3, the R2 parameter was 0.57, 0.62 and 0.65 , respectively; i.e., the carbon ordering of the ShR 1 is the highest, and that of the Sh1 is the lowest in a series of selected samples.

To assess vanadium distribution in shungite rocks, element distribution maps were compiled using scanning electron microscopy and EDS (Fig. 7). The elements of greatest interest are (1) carbon, which shows the distribution of the most abundant constituent of shungite, (2) oxygen, which is mainly associated with mineral components, (3) vanadium, and (4) chromium. The zirconium distribution is presented as a control for noise estimation. From the distribution of carbon and oxygen, it can be seen (Fig. 7) that a shungite 
(a)

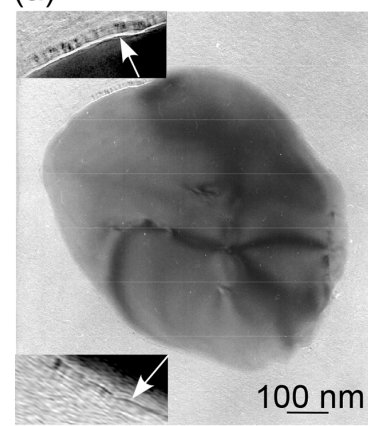

(b)

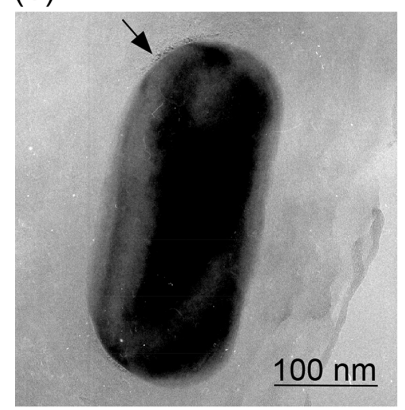

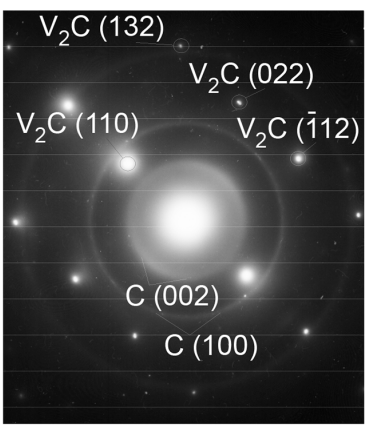
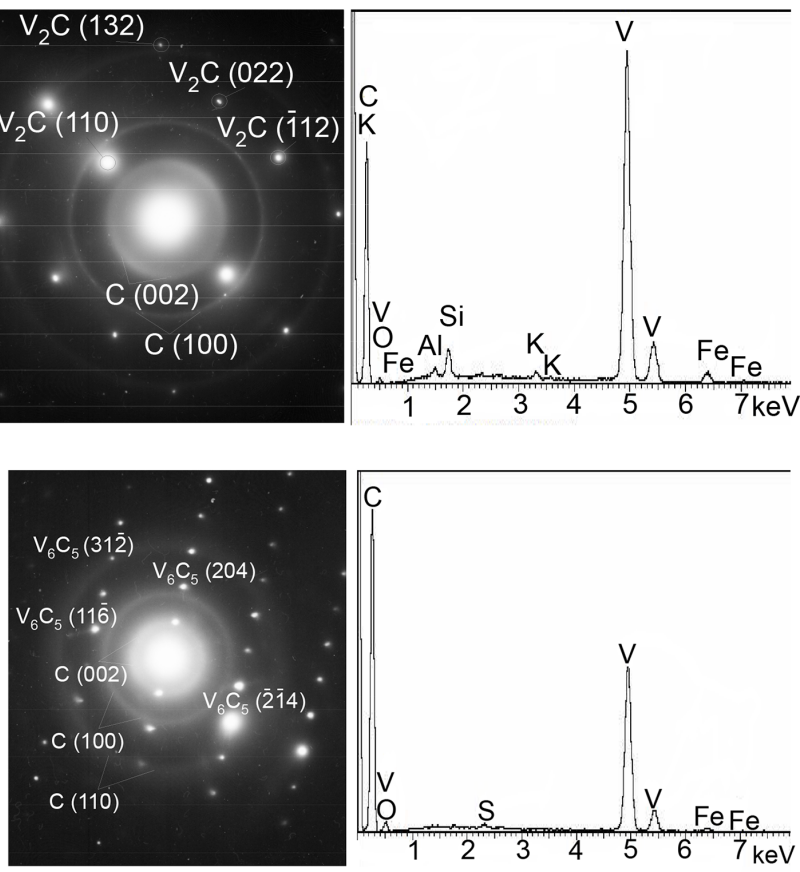

Figure 3. TEM images and corresponding SAED patterns, as well as the EDS spectra of single crystals of compositionally variable vanadium carbides in Sh1 samples: (a) $\mathrm{V}_{2} \mathrm{C}$ (ICDD - 01-071-1258) and (b) $\mathrm{V}_{6} \mathrm{C}_{5}$ (ICDD - 01-080-2287). Vanadium carbides display point diffraction maxima, while shungite (turbostratic layering) exhibits ring diffraction maxima. The ordered carbon film on the surface of micro-sized minerals is indicated by arrows.
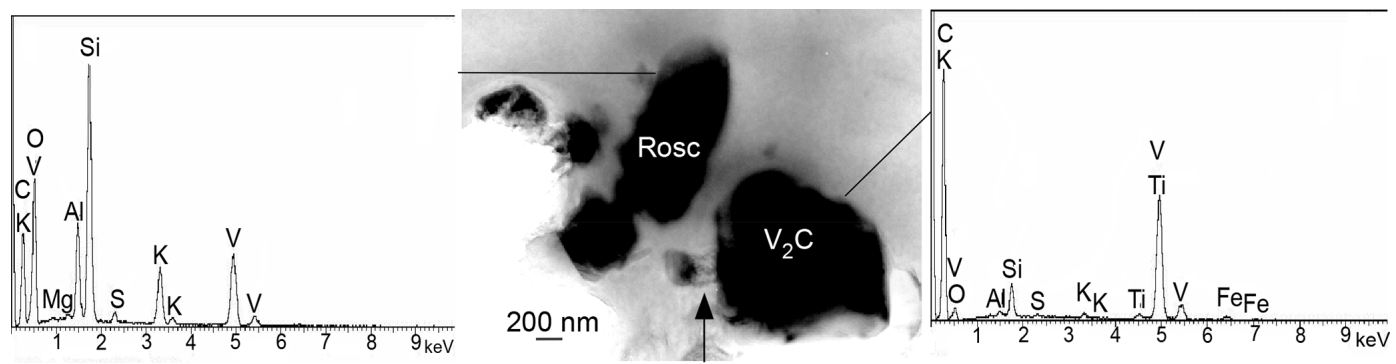

Figure 4. Paragenesis of vanadium carbide and roscoelite with corresponding EDS spectra in Sh1 samples. Three nano-sized regions with an increased vanadium content are indicated by an arrow.

rock is a combination of interpenetrating carbon and mineral components. Carbon does not form separate regions when its concentration of $22 \mathrm{wt} \%$ provides good electrical conductivity of the rock.

The distribution of all chemical elements is associated with rock-forming and accessory minerals varying in size from a few micrometers to less than $1 \mu \mathrm{m}$. However, vanadium, at a concentration of $400 \mathrm{ppm}$ in this rock, is distributed very uniformly and is not associated with the minerals visible on scanning electron microscopic images. On the contrary, a redox-dependent metal, e.g., $\mathrm{Cr}$ at a significantly lower concentration of $176 \mathrm{ppm}$, is mainly concentrated in visible accessory minerals several micrometers in size (Fig. 7). Note that the observed fine distribution of vana- dium is not background noise. This can be seen when comparing the distribution maps of vanadium and zirconium. Zirconium is visible on the map as a zircon in the complete absence of the background.

One of the most essential electro-physical properties is the shielding effectiveness that is currently relevant for the search for and creation of materials used for reducing the influence of anthropogenic electromagnetic background on electronics and biological objects. The shielding effectiveness was determined in a wide frequency range for selected shungite rocks (Fig. 8). The data obtained showed no correlation between carbon ordering and shielding effectiveness for samples at the same carbon concentration. However, shielding effectiveness is highest for sample ShR1 with elevated 


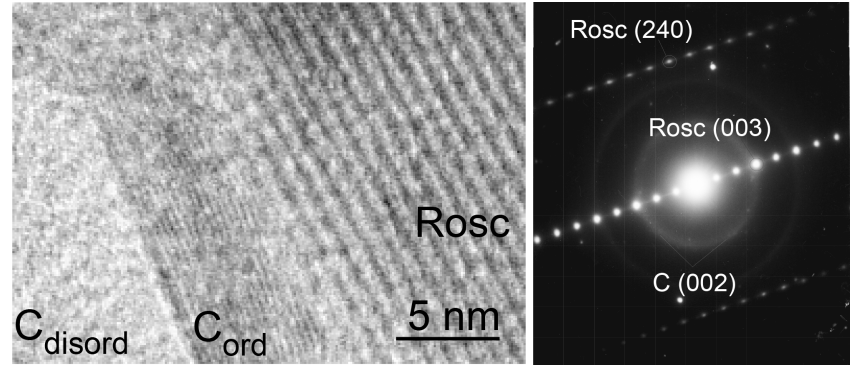

Figure 5. Fragment of an partially ordered carbon film at the surface of roscoelite and its corresponding SAED pattern (ICDD - 00-0100496) in Sh1 samples.
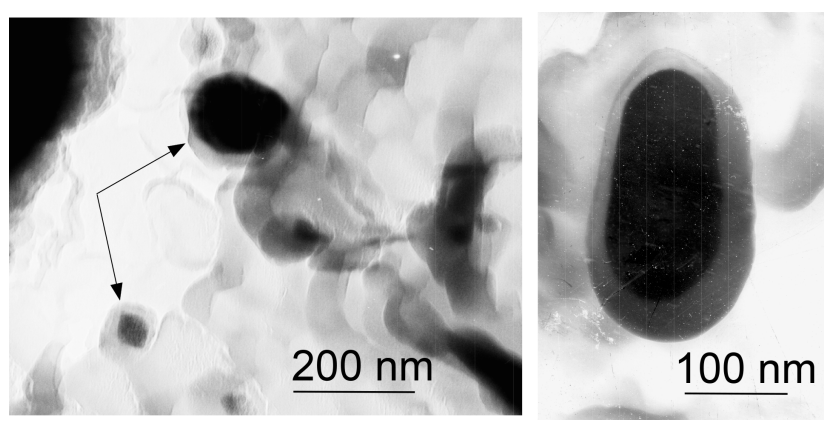

Figure 6. TEM images of micro-and nano-scale particles encapsulated by carbon shells (arrows) that were found in ShR1.

vanadium concentration and the presence of particles encapsulated in carbon shells. In this regard, it has also been shown that vanadium carbides enclosed in a carbon shell have impressive electrochemical characteristics and clear prospects for practical application as the most stable materials for batteries (Mahajan et al., 2020).

\section{Discussion}

Shungite-bearing deposits have attracted considerable interest because of their complex (volcanogenic sedimentary) conditions of formation, huge reserves, a unique structure of carbonaceous matter and multi-directional practical application (Grew, 1974; Buseck et al., 1997; Melezhik et al., 1999; van Zuilen et al., 2012; Strauss et al., 2013; Deines et al., 2020). Shungite rocks form a large, diverse group of black Lower Proterozoic rocks, 2.0-2.1 Ga in age, all of which contain free carbon. The formation of shungite rocks was associated with synchronous magmatic activity in addition to providing metasomatic fluids during rifting and associated magmatism (Buseck et al., 1997). The shungite rocks were deformed and underwent greenschist-facies metamorphism during the $1.8 \mathrm{Ga}$ Svecofennian orogeny. The paragenesis chlorite-actinolite-epidote reflects a temperature of 300-350 ${ }^{\circ} \mathrm{C}$ (Melezhik et al., 1999). At the same time, the genesis of carbonaceous matter and its structural state raises a number of questions. In particular, why is shungite, according to high-resolution electron microscopy, similar to kerogen heated to a temperature above $2000^{\circ} \mathrm{C}$ (Jehlicka and Rouzaud, 1993) or coke formed at a temperature of $2500^{\circ} \mathrm{C}$ (Kovalevski et al., 2001). The study of the mineral components of shungite rocks is of significant interest in general.

The difference in the forms of vanadium carbide in shungite is difficult to explain, assuming that they were formed simultaneously under the same conditions, for example, from vanadium-containing metalloporphyrins and/or nonporphyrins. According to the two more recent phase diagrams calculated for the $\mathrm{V}-\mathrm{C}$ binary system (Hu et al., 2006; Okamoto, 2010), $\mathrm{V}_{2} \mathrm{C}$ and $\mathrm{V}_{6} \mathrm{C}_{5}$ can coexist at low temperatures in bulk compositions between $\sim 33 \%$ and $\sim 44 \%$ (atomic) carbon. Orthorhombic $\left(\mathrm{V}_{2} \mathrm{C}\right)$ and monoclinic $\left(\mathrm{V}_{6} \mathrm{C}_{5}\right)$ vanadium carbide could be formed at temperatures below 800 and $1150^{\circ} \mathrm{C}$, respectively (Lipatnikov et al., 1999; Hu et al., 2006), which are comparable to magmatic temperatures in nature (Persikov et al., 2020). Indeed, the formation of shungite rocks was accompanied by explosive volcanism and, possibly, underwater hydrothermal activity (Melezhik et al., 1999). Therefore, the formation of vanadium carbides is more plausibly associated with synchronous volcanism, which provided the main source of heat and contributed to the flow of additional substances.

The presence of micro-sized particles of vanadium carbides encapsulated in the carbon shell in shungite is very unexpected for a rock formed under greenschist-facies conditions and directly raises the question of determining the source paths of vanadium. If we assume that vanadium was derived from organo-vanadium complexes of organic matter, then we need to identify a mechanism explaining how vanadium was sufficiently concentrated to crystallize into micro-sized particles of $\mathrm{V}$ carbide. One possible mechanism is suggested by the processes involved in concentrating and encapsulating $\mathrm{V}$ carbide in a carbon shell during mechanical and chemical synthesis in a planetary mill (Mahajan et al., 2020). In the case of shungite, it is unlikely that during the migration of the parent carbonaceous matter, conditions of mechanochemical synthesis, comparable to vigorous processes in a planetary mill, could be achieved. In addition, the morphostructures of carbon differ in shungite; the formation of an ordered layer occurs only on the surface of the particles, whereas during mechanochemical synthesis, carbon consists entirely of such more ordered layers. Due to this difference we cannot regard the above mechanism as the cause of the formation of vanadium carbides in shungite.

Given that the nano-sized grains of $\mathrm{V}_{2} \mathrm{C}$ and $\mathrm{V}_{6} \mathrm{C}_{5}$ in shungite are all single crystals and that some are facetted, Edward Grew (personal communication, 2021) suggested that the grains could be sublimates. That is, the crystals were deposited from a vapor and subsequently were encapsulated in a partially ordered film of carbon. Highly reduced gases might have transported $\mathrm{V}$ to the $\mathrm{C}$-rich layers. These gases might have been heated by the volcanic activity. Similar 

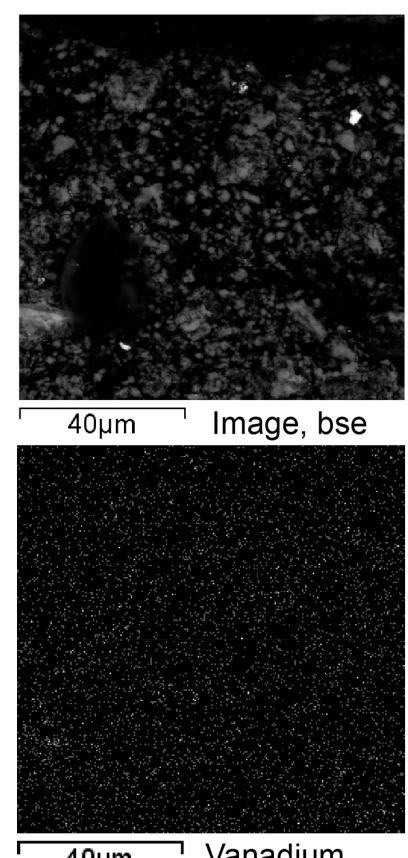

$40 \mu \mathrm{m}$
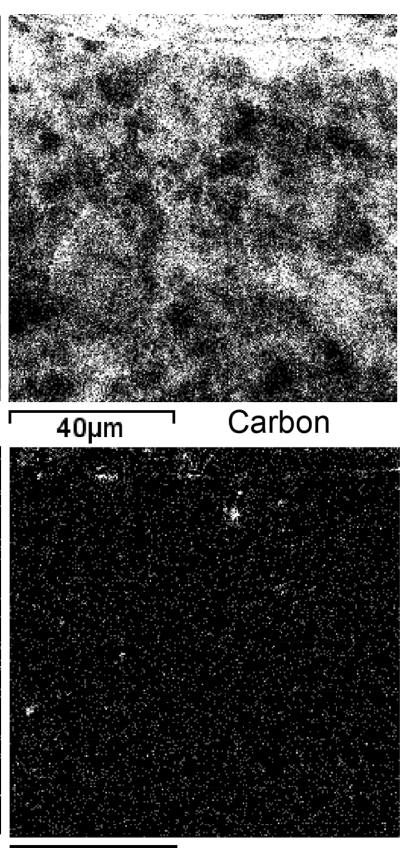

$40 \mu \mathrm{m}$ Chromium
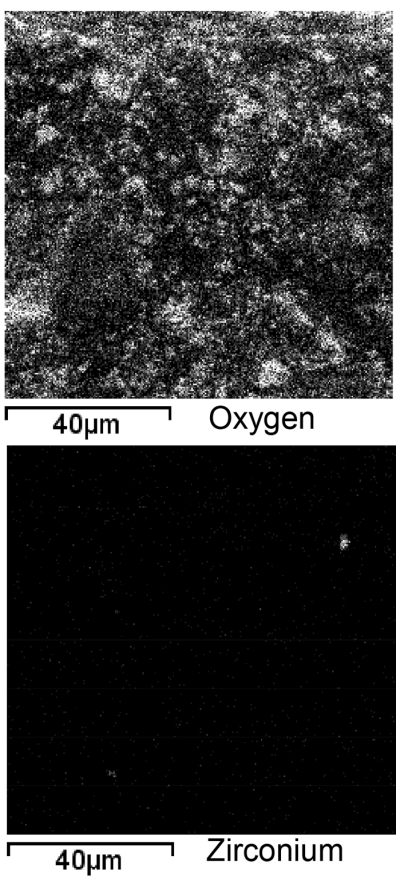

Figure 7. Element distribution maps of the region shown in the backscattered electron (BSE) image of ShR1.

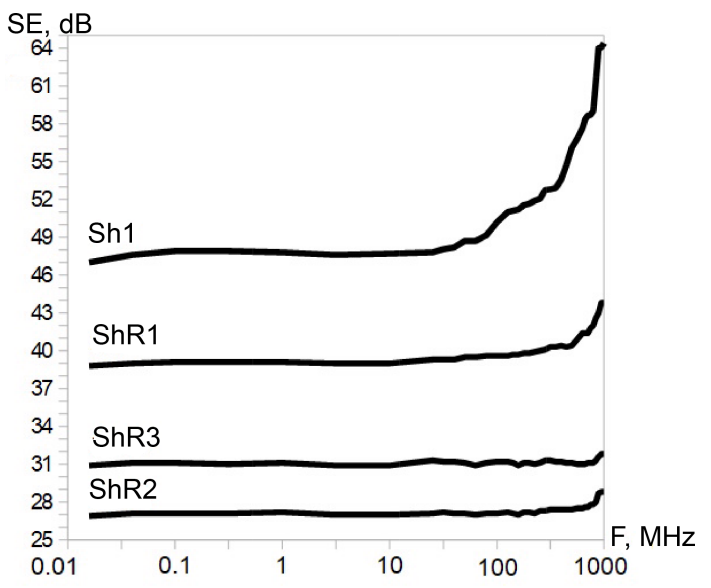

Figure 8. Dependence of the shielding effectiveness (SE) of shungite rocks on the electromagnetic field frequency (in $\mathrm{MHz}$ ). SE is in decibels $(\mathrm{dB})$, a relative unit of measurement that expresses the ratio of two values of a power quantity on a logarithmic scale.

syntheses in the laboratory were reported by Bandow and Saito (1993) and Saito (1995), which involved the evaporation of $\mathrm{V}$ carbide that then sublimated as single crystals encapsulated in partially ordered carbon. It is also possible that vanadium was introduced into the shungite parent substance in the form of high-temperature particles. At the surface of the vanadium-bearing particle, the carbonaceous substance was pyrolyzed, and the carbon was dissolved within the particle, the amount of which was controlled by the temperature of the particle. When the particle cooled, carbon was released on the surface in the form of a carbon layer, and the carbon remaining in the particle volume was involved in the formation of metal carbides. Crystallization of those occurs into equilibrium forms at low temperatures, which according to the V-C binaries (Hu et al., 2006; Okamoto, 2010) could be $\mathrm{V}_{2} \mathrm{C}$ and $\mathrm{V}_{6} \mathrm{C}_{5}$. A similar synthesis of nano- and micro-sized particles encapsulated in carbon shells was reported in the laboratory (Kovalevski and Safronov, 1998).

It is noted in the literature that carbon in the form of closed shells is one of the most chemically resistant substances in nature, even at high temperatures (Saito, 1995). At the same time, the carbon network of atoms is impervious to most light and other atoms, which prevents the diffusion of atoms both from and into a carbon shell. Thus, carboncoated materials (or encapsulated materials) are reliably isolated from the external environment and protected from diffusion changes. In particular, when studying reactively active crystals of lanthanum carbide $\left(\mathrm{LaC}_{2}\right)$ enclosed in carbon shells, it was found that metals enclosed in carbon form a new class of materials that can be protected from external influences for a long time (Ruoff et al., 1993). In this regard, the carbon shells themselves, based on their size, air tightness and ability to protect the contents, were called "nanocapsules" (Saito, 1995). The encapsulation of vanadium carbides in carbon shells explains their good preservation in shungite for 2.0-2.1 billion years. It is possible that the decomposition of vanadium carbides due to the destruction of carbon shells with the formation of roscoelite occurred during the $1.8 \mathrm{Ga}$ Svecofennian orogeny when the sediments were affected by greenschist-facies metamorphism (Melezhik et al., 1999). 
This mechanism involves the introduction of hightemperature particles with a high content of vanadium into the parent carbonaceous substance. In this regard, according to some authors, the source of vanadium in many settings is associated with volcanic events (Nahar, 2017; White, 2010). In these events, the behavior of related redox-sensitive elements such as $\mathrm{Fe}, \mathrm{V}$ and $\mathrm{Cr}$ is controlled by redox conditions during magmatic differentiation (Nicklas et al., 2016). Recently, in the course of experiments on the segregation of metals in a basalt melt during its interaction with hydrogen, the formation of initially small (several micrometers) spheres of metal, which then coalesce (merge) during the experiment, has been established (Persikov et al., 2020). In this case, metal segregations in the basalt melt are formed at a temperature significantly lower than the melting point of the metal phase and correspond to real magmatic temperatures in nature $\left(\leq 1250^{\circ} \mathrm{C}\right)$. It is assumed that in the earth's crust, either reduced fluids $\left(\mathrm{H}_{2}, \mathrm{H}_{2}+\mathrm{CH}_{4}\right)$ or carbon-containing matter that reacts with basaltic magma can participate in the formation of native metals (Persikov et al., 2020). It is also noted that the condition for the co-deposition of native metals (for example, iron) and silicate minerals in terrestrial magmatic systems is the assimilation of highly reduced organic material rich in $\mathrm{C}$, including carbonaceous shales or hydrocarbon-rich rocks. Under such reducing conditions, $\mathrm{Fe}$ predominantly forms $\mathrm{Fe}-\mathrm{C}$ metal alloys, which have eutectic temperatures similar to typical basaltic magmas $\left(\approx 1200^{\circ} \mathrm{C}\right)$ (Pernet-Fisher et al., 2017). Nevertheless, it should be noted that an answer about the source paths of vanadium in shungite remains a conundrum from the point of view of modern geological ideas about the formation of shungite.

\section{Conclusions}

Four types of shungite rocks containing $98.2 \mathrm{wt} \% \mathrm{C}$, $22.2 \mathrm{wt} \% \mathrm{C}, 21.6 \mathrm{wt} \% \mathrm{C}$ and $22.4 \mathrm{wt} \% \mathrm{C}$ and $416,311,78$ and $182 \mathrm{ppm} \mathrm{V}$ were studied. The presence of two vanadium carbides, $\mathrm{V}_{2} \mathrm{C}$ and $\mathrm{V}_{6} \mathrm{C}_{5}$, in samples of shungite with a content of $98.2 \mathrm{wt} \% \mathrm{C}$ have been revealed by energy dispersive spectroscopy and selected-area electron diffraction. The vanadium carbides revealed are monocrystalline and encapsulated in a carbon shell, and these are the first wellcrystallized natural examples of $\mathrm{V}$ carbides. The encapsulation of vanadium carbides in carbon shells explains their good preservation for 2.0-2.1 billion years. The parageneses of vanadium carbide and roscoelite indicate that roscoelite in shungite rocks may be a secondary mineral formed upon vanadium carbide decomposition. The decomposition of vanadium carbides due to the destruction of carbon shells with the formation of roscoelite could have occurred during the $1.8 \mathrm{Ga}$ Svecofennian orogeny when the sediments were affected by greenschist-facies metamorphism. Particles encapsulated in carbon shells were also revealed in the shungite rock containing $22.2 \mathrm{wt} \% \mathrm{C}$ and $311 \mathrm{ppm} \mathrm{V}$, for which high shielding effectiveness is observed in a wide frequency range.

Data availability. All data derived from this research are presented in the enclosed tables and figures in the main text and the Supplement.

Supplement. The supplement related to this article is available online at: https://doi.org/10.5194/ejm-34-131-2022-supplement.

Author contributions. VVK developed the idea, conducted TEM and HRTEM experiments, performed data analysis, and supervised the preparation of the paper. IAM conducted EM experiments and subjected the samples to SEM and electron microprobe analysis. Both authors contributed equally to the discussion.

Competing interests. The contact author has declared that neither they nor their co-author has any competing interests.

Disclaimer. Publisher's note: Copernicus Publications remains neutral with regard to jurisdictional claims in published maps and institutional affiliations.

Acknowledgements. The authors thank Peter R. Buseck for the possibility to use high-resolution electron microscopy at ASU, Arizona, USA. We are grateful to Edward S. Grew for the discussion and the assumption that nanocrystals of vanadium carbides maybe sublimate, as well as for comments, recommendations and edits in English that helped to improve this paper. We also thank Ferraris Giovanni for his valuable comments and edits. The authors also thank Gregory N. Sokolov for correcting the English manuscript. TEM, SEM and Raman spectroscopy studies were performed at the Analytical Center, Karelian Research Center

Financial support. The work was funded from the Federal budget for the accomplishment of KarRC RAS (IG KarRC RAS) Research Project AAAA-A18-118020690238-0).

Review statement. This paper was edited by Cristiano Ferraris and reviewed by Edward Grew and Ferraris Giovanni.

\section{References}

Bandow, S. and Saito, Y.: Encapsulation of $\mathrm{ZrC}$ and $\mathrm{V}_{4} \mathrm{C}_{3}$ in graphite nanoballs via arc burning of metal carbides/graphite composites, Jpn. J. Appl. Phys. 32, L1677-L1680, 1993.

Baumgartner, R. J., Van Kranendonk, M. J., Fiorentini, M. L., Pagès, A., Wacey, D., Kong, C., Saunders, M., and Ryan, C.: Formation of micro-spherulitic barite in association with organic 
matter within sulfidized stromatolites of the 3.48 billion-year-old Dresser Formation, Pilbara Craton, Geobiology, 18, 415-425, https://doi.org/10.1111/gbi.12392, 2020.

Beyssac, O., Goffé, B., Chopin, C., and Rouzaud, J.-N.: Raman spectra of carbonaceous material in metasediments: a new geothermometer, J. Metamorph. Geol., 20, 859-871, 2002.

Beyssac, O., Goffe, B., Petitet, J.-P., Froigneux, E., Moreau, M., and Rouzaud, J.-N.: On the characterization of disordered and heterogeneous carbonaceous materials by Raman spectroscopy, Spectrochim. Acta A, 59, 2267-2276, https://doi.org/10.1016/S13861425(03)00070-2, 2003.

Bielowicz, B.: Changes in the spontaneous combustion tendency of humic coals according to their petrographic composition and physico-chemical properties, Gospod. Surowcami. Min., 36, 197-218, https://doi.org/10.24425/gsm.2020.132561, 2020.

Bindi, L., Cámara, F., Gain, S. E. M., Griffin, W. L., Huang, J.-X., Saunders, M., and Toledo, V.: Kishonite, $\mathrm{VH}_{2}$, and Oreillyite, $\mathrm{Cr}_{2} \mathrm{~N}$, Two New Minerals from the Corundum Xenocrysts of Mt Carmel, Northern Israel, Minerals, 10, 1118, https://doi.org/10.3390/min10121118, 2020.

Buseck, P. R., Galdobina, L. P., Kovalevski, V. V., Rozhkova, N. N., Valley, J. W., and Zaidenberg, A. Z.: Shungites: the C-rich rocks of Karelia, Russia, Can. Mineral., 35, 1363-1378, 1997.

Chazhengina, S. Y. and Kovalevski, V. V.: Raman spectroscopy of weathered shungites, J. Raman Spectrosc., 48, 1590-1596, https://doi.org/10.1002/jrs.5188, 2017.

Cornelius, C. D.: Classification of natural bitumen: A physical and chemical approach. Exploration for Heavy Crude Oil and Natural Bitumen, edited by: Meyer, R. F., AAPG Studies in Geology, 25, Amer. Assoc. Petroleum Geologists, Tulsa, OK, 165-174, 1987.

Deines, Y. E., Kovalevski, V. V., Kochneva, I. V., Moshnikov, I. A., and Rozhkova, V. S.: Physical and chemical properties of shungite rocks from different stratigraphic levels of the Zaonega formation, Trudy KarNC RAN, Ser. Geologiya Dokembriya, 2, 8489, https://doi.org/10.17076/geo1187, 2020.

Filby, R. H.: Origin and nature of trace element species in crude oils, bitumens and kerogens: implications for correlation and other geochemical studies, Geol. Soc. Lond. Spec. Publ., 78, 203-219, https://doi.org/10.1144/GSL.SP.1994.078.01.15, 1994.

Golubev, A. I. and Galdobina, L. P.: Carbon-bearing rocks of the Zaonezhskaya formation of the Lower Proterozoic of Karelia and their geochemical specialization, Problems of sedimentary geology of the Precambrian, 10, edited by: Lazur, O. G. and Belov A. N., Nauka, Moscow, 100-105, https://www.geokniga.org/bookfiles/ geokniga-problemy-osadochnoy-geologii-dokembriya-vypusk- 10 . pdf (last access: 11 February 2022), 1985 (in Russian).

Grew, E. S.: Carbonaceous material in some metamorphic rocks of New England and other areas, J. Geol., 82, 50-73, 1974.

Gustafsson, J. P.: Vanadium geochemistry in the biogeosphere - speciation, solid-solution interactions, and ecotoxicity, Appl. Geochem., 102, 1-25, https://doi.org/10.1016/j.apgeochem.2018.12.027, 2019.

Hu, J., Li, C., Wang, F., and Zhang, W.: Thermodynamic reassessment of the V-C system, J. Alloy. Compd., 421, 120-127, https://doi.org/10.1016/j.jallcom.2005.11.033, 2006.

Jehlicka, J. and Rouzaud, J. N.: Transmission electron microscopy of carbonaceous matter in Precambrian shungite from Karelia, Bitumens in Ore Deposits, edited by: Parnell, J.,
Kucha, H., and Landais, P., Springer Verlag, Berlin, 53-60, https://doi.org/10.1007/978-3-642-85806-2, 1993.

Ketris, M. P. and Yudovich, Y. E.: Estimations of clarkes for carbonaceous biolithes: World averages for trace element contents in black shales and coals, Int. J. Coal Geol., 78, 135-148, https://doi.org/10.1016/j.coal.2009.01.002, 2009.

Kovalevski, V. V. and Safronov, A. N.: Pyrolysis of hollow carbons on melted catalyst, Carbon, 36, 963-968, https://doi.org/10.1016/S0008-6223(97)00223-6, 1998.

Kovalevski, V. V., Buseck, P. R., and Cowley, J. M.: Comparison of carbon in shungite rocks to other natural carbons: an X-ray and TEM study, Carbon, 39, 243-256, https://doi.org/10.1016/S0008-6223(00)00120-2, 2001.

Lipatnikov, V. N., Gusev, A. I., Ettmayer, P., and Lengauer, W.: Phase transformations in non-stoichiometric vanadium carbide, J. Phys.: Condens. Matter, 11, 163-184, https://doi.org/10.1088/0953-8984/11/1/014, 1999.

Mahajan, M., Roy, K., Parmar, S., Singla, G., Pandey, O. P., Singh, K., Vaidhyanathan, R., and Ogale, S.: Room temperature processed in-situ carbon-coated vanadium carbide (VC@C) as a high capacity robust Li/Na battery anode material, Carbon, 161, 108-116, https://doi.org/10.1016/j.carbon.2020.01.057, 2020.

Marakushev, A. A. and Marakushev, S. A.: Formation of oil and gas fields, Lithol. Miner. Resour., 43, 454-469, 2008.

Melezhik, V. A., Fallick, A. E., Filippov, M. M., and Larsen O.: Karelian shungite - an indication of 2.0-Ga-old metamorphosed oil-shale and generation of petroleum: geology, lithology and geochemistry, Earth-Sci. Rev., 47, 1-40, 1999.

Moshnikov, I. A. and Kovalevski, V. V.: Composite materials based on nanostructured shungite filler, Mater. Today-Proc., 5, 2597125975, https://doi.org/10.1016/j.matpr.2018.08.014, 2018.

Nahar, M. S.: The use of $\delta^{18} \mathrm{O}$ as an indicator of vanadium movement in a dormant stratovolcano region, Toxicol. Environ. Chem., 99, 735-752, https://doi.org/10.1080/02772248.2017.1338701, 2017.

Nicklas, R. W., Puchtel, I. S., and Richard, D.: Ash High-precision determination of the oxidation state of komatiite lavas using vanadium liquid-mineral partitioning, Chem. Geol., 433, 36-45, https://doi.org/10.1016/j.chemgeo.2016.04.011, 2016.

Okamoto, H.: C-V (Carbon-Vanadium), J. Phase Equilib. Diff., 31, 91-92, https://doi.org/10.1007/s11669-009-9637-4, 2010.

Ostrooumov, M. and Taran, Y.: Vanadium, V - a new native element mineral from the Colima volcano, State of Colima (Mexico), and implications for fumarole gas composition, Mineral. Mag., 80, 371-382, https://doi.org/10.1180/minmag.2016.080.006, 2016.

Parnell, J.: Metal enrichments in solid bitumens: A review, Mineral. Deposita, 23, 191-199, 1988.

Pernet-Fisher, J. F., Day, J. M. D., Howarth, G. H., Ryabov, V. V., and Taylor, L. A.: Atmospheric outgassing and native-iron formation during carbonaceous sediment-basalt melt interactions, Earth Planet. Sc. Lett., 460, 201-212, https://doi.org/10.1016/j.epsl.2016.12.022, 2017.

Persikov, E. S., Bukhtiyarov, P., Aranovich, L. Y., and Shchekleina, M. D.: Features of basaltic melt-hydrogen interaction at hydrogen pressure $10-100 \mathrm{MPa}$ and temperature $1100-1250^{\circ} \mathrm{C}$, Chem. Geol., 556, 119829, https://doi.org/10.1016/j.chemgeo.2020.119829, 2020.

Premovič, P. I., Nikolič, N. D., Pavlovič, M. S., Jovanovič, L. S., and Premovič, M. P.: Origin of vanadium in coals: 
Parts of the Western Kentucky (USA) No. 9 coal rich in vanadium, Geol. Soc.-Lond. Spec. Publ., 125, 273-286, https://doi.org/10.1144/GSL.SP.1997.125.01.24, 1997.

Rogerson, M., Mercedes-Martín, R., Brasier, A. T., McGill, R. A. R., Prior, T. J., Vonhof, H., Fellows, S. M., Reijmer, J. J. G., McClymont, E., Billing, I., Matthews, A., and Pedley, M.: Are spherulitic lacustrine carbonates an expression of large-scale mineral carbonation? A case study from the East Kirkton Limestone, Scotland, Gondwana Res., 48, 101-109, https://doi.org/10.1016/j.gr.2017.04.007, 2017.

Ruoff, R. S., Lorents, D. C., Chan, B., Malhotra, R., and Subramoney, S.: Single crystal metals encapsulated in carbon nanoparticles, Science, 259, 346-348, 1993.

Saito, Y.: Nanoparticles and filled nanocapsules, Carbon, 33, 979988, 1995

Strauss, H., Melezhik, V. A., Lepland, A., Fallick, A. E., Hanski, E. J., Filippov, M. M., Deines, Y. E., Illing, C. J., Črne, A. E., and Brasier, A. E.: Enhanced Accumulation of Organic Matter: The Shunga Event, Reading the Archive of Earth's Oxygenation. Volume 3: Global Events and the Fennoscandian Arctic RussiaDrilling Early Earth Project, Series: Frontiers in Earth Sciences, edited by: Melezhik, V. A., Prave, A. R., Fallick, A.E., Kump, L. R., Strauss, H., Lepland, A., and Hanski, E. J., Springer, Heidelberg, 1195-1273, https://doi.org/10.1007/978-3-642-29670-3_6, 2013.
Svetov, S. A., Stepanova, A. V., Chazhengina, S. Y., Svetova, E. N., Mikhailova, A. I., Rybnikova, Z. P., Paramonov, A., Utitsina, V. L., Kolodei, V. S., and Ekhova, M. V.: Precise ICPMS and LA-ICP-MS analysis of rock and mineral composition: Technique application and assessment of accuracy of the obtained results on the example of Early Precambrian mafic complexes, Tr. Karel. Nauchn. Tsentr Ross. Akad. Nauk., 7, 54-73, https://doi.org/10.17076/geo140, 2015.

van Zuilen, M. A., Fliegel, D., Wirth, R., Lepland, A., Qu, Y., Schreiber, A., Romashkin, A. E., and Philippot, P.: Mineral-templated growth of natural graphite films, Geochim. Cosmochim. Ac., 83, 252-262, https://doi.org/10.1016/j.gca.2011.12.030, 2012.

White, W. B.: Secondary minerals in volcanic caves: data from Hawai'i, J. Cave Karst Stud., 72, 75-85, https://doi.org/10.4311/jcks2009es0080, 2010. 